\title{
CONTINUOUS WARM REPERFUSION DURING HEART TRANSPLANTATION
}

Gonzalo Pradas, $\mathrm{MD}^{\mathrm{a}}$

Jose Cuenca, MD

Alberto Juffé, MD

\begin{abstract}
From April 1991 to January 1993, 37 orthotopic heart transplantations were performed at our institution. Conventional preservation technique with cold crystalloid cardioplegia and topical hypothermia during storage and implantation was used in the first 15 cases (group A). After January 1992, for the next 22 patients (group B), we administered a first dose of hyperkalemic blood cardioplegia on arrival of the graft and thereafter instituted continuous warm reperfusion by infusion of oxygenated blood with added potassium. The groups were compared retrospectively, and significant differences were observed. In group B, the ischemic time was shortened by 31 minutes, the suture time lasted 12 minutes longer, sinus rhythm recovered spontaneously, the duration of inotropic support was reduced, postoperative arrythmias decreased, length of intensive care and hospital stays were reduced, there was less ischemic damage in the first endomyocardial biopsy sample, and right ventricular pressures a month after operation were lower. Continuous warm reperfusion during implantation of the donor heart is technically feasible and seems to provide enhanced myocardial preservation. (J THORAC CARDIOVASC SuRG 1996;111: 784-90)
\end{abstract}

$\mathrm{H}$ igh hospital mortality rates from primary graft failure (25\% of all deaths) ${ }^{1}$ and more frequent use of "suboptimum" donors because of the scarcity of donor organs ${ }^{2}$ have caused renewed interest in perfecting cardiac preservation techniques ${ }^{3}$ during heart transplantation. Even in uncomplicated heart transplantation, it is possible during the first 24 to 48 hours after operation to observe transitory hemodynamic and electrical instability. ${ }^{4,5}$ When this temporary phenomenon occurs in hearts with previously normal function, it is attributable to a certain degree of myocardial "stunning.",6-9

In a recent survey, Wheeldon and coworkers ${ }^{3}$ observed that some form of reperfusion is used in $55 \%$ of 92 transplant centers worldwide. Most of these centers infuse intermittent doses of cold blood or cold oxygenated crystalloid cardioplegia during

From the Cardiac Surgery Unit "Cardiovigo," Hospital do Meixoeiro, Vigo, ${ }^{\text {a }}$ and Service of Cardiac Surgery, Hospital Juan Canalejo, La Coruña,' Spain.

Received for publication August 19, 1994; accepted for publication June 7, 1995.

Address for reprints: Gonzalo Pradas, MD, Unidad de Cirugía Cardíaca "Cardiovigo," Hospital do Meixoeiro, Apdo. Oficial s/n, 36200-Vigo, Pontevedra, Spain.

Copyright (C) 1996 by Mosby-Year Book, Inc.

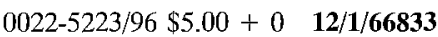

implantation of the heart and thereafter administer normothermic blood reperfusion doses ("hot shots") according to Buckberg's preservation technique. ${ }^{10-13}$

In contrast, Menasché ${ }^{14}$ uses continuous normothermic blood cardioplegia after completion of the left atrial anastomosis, a technique derived from the "warm surgery" principles recently introduced by Salerno, Houck, and Barrozo. ${ }^{15}$

We employed the conventional preservation technique (cold crystalloid cardioplegia and cold storage $)^{16,17}$ until January 1992 . Thereafter we developed our own technique of reperfusion, combining Buckberg's theories to reduce reperfusion damage $^{18-20}$ with continuous normothermic blood cardioplegia to oxygenate and supply the metabolic requirements of the myocardial cells under normothermia, thereby attempting some degree of cellular repair. ${ }^{15,21,22}$ In this article, we describe the new technique and results of a retrospective comparative analysis of these two techniques of donor heart preservation.

\section{Materials and methods}

From April 1991 to January 1993, 37 orthotopic heart transplantations were performed at our institution. In the first 15 cases (group A), until December 1991, a conventional preservation technique was employed, with the infusion of $1000 \mathrm{ml}$ of extracellular crystalloid cardioplegia ( $30 \mathrm{mEq} / \mathrm{L}$ potassium chloride) at $4^{\circ} \mathrm{C}$ for induction of 
Table I. Cardioplegic solutions

\begin{tabular}{lcc}
\hline & Induction & Reperfusion \\
\hline $\begin{array}{l}\text { (2 mEq/ml) Potassium } \\
\text { chloride solution (ml) }\end{array}$ & 15 & 40 \\
Potassium chloride sol- & 30 & 80 \\
$\quad$ ute (mEq) & & \\
0.3 mol/L THAM solu- & - & 225 \\
$\quad$ tion (ml) & & \\
THAM solute (mEq) & - & 68 \\
CPD (ml) & - & 225 \\
Aspartate/glutamate (ml) & - & 250 \\
$5 \%$ dextrose (ml) & - & 200 \\
$50 \%$ dextrose (ml) & 82 & - \\
Sodium chloride (mEq) & 0.5 & - \\
Calcium chloride (mEq) & 5 & - \\
Glucose (gm) & 10 & - \\
Mannitol (gm) & 30 & - \\
NaCO ${ }_{3} H$ 1 mol/L (ml) & q.s. & - \\
Injectable water & 8.6 & 8.26 \\
pH & 369 & 627 \\
Osmolarity (mOsm) & 1000 & 1000 \\
Total volume (ml) &
\end{tabular}

THAM, Tris(hydroxymethyl)aminomethane; $C P D$; citrate-phosphate-dextrose solution; $q$.s., a sufficient quantity.

cardiac arrest (Table I), subsequent transportation and storage with the same cardioplegic solution at $4^{\circ} \mathrm{C}$, local hypothermia during implantation, and systemic temperature of $28^{\circ} \mathrm{C}$ during extracorporeal circulation.

Since January 1992, in the last 22 transplant cases (group B), the same solution and dosage of crystalloid cardioplegia were used for induction of cardiac arrest and transportation. While extracorporeal circulation was established with hypothermia at $32^{\circ}$ to $34^{\circ} \mathrm{C}$ and the recipient heart was being removed, the donor heart was removed from the refrigerator and trimmed as usual for implantation at room temperature.

The aortic root of the donor was stappled just distal to the brachiocephalic trunk with the Multifire TA 55-4.8 stapler (United States Surgical Corp., Norwalk, Conn.) and an aortic root cannula (model 10012, DLP Inc., Grand Rapids, Mich.) was positioned in the ascending aorta. At this moment, antegrade reperfusion of the heart was begun with a (4:1) solution of blood cardioplegia, Buckberg type, at $30^{\circ}$ or $32^{\circ} \mathrm{C}$ during 5 minutes. This solution was glutamate-aspartate enriched and had a high concentration of potassium $(20 \mathrm{mEq} / \mathrm{L})$ to avoid premature cardiac action (Table I). The ratio of blood to cardioplegia (4:1) was achieved with the Shiley BCD PLUS system (Mallinckrodt Medical TPI, Inc., Irvine, Calif.). The initial reperfusion flow was $250 \mathrm{ml} / \mathrm{min}$ or less to maintain a low perfusion pressure (50 to $60 \mathrm{mmHg}$ ) and a competent aortic valve.

A retrograde perfusion cannula (Research Medical Retroplegia Cannula RC-014 T, 14F, self-inflating balloon; Research Industries Corp., Midvale, Utah) was then introduced into the coronary sinus and fixed with a pursestring suture (Prolene 4-0; Ethicon, Inc., Somerville, N.J.) around the coronary sinus orifice, with the knot
Table II. Potassium chloride infusion rate

\begin{tabular}{cccc}
\hline \multirow{2}{*}{$\begin{array}{c}\text { Serum } \\
\text { potassium }\end{array}$} & \multicolumn{3}{c}{ Retrograde } \\
\cline { 2 - 4 }$(\mathrm{mEq} / \mathrm{L})$ & $100 \mathrm{ml} / \mathrm{min}$ & $150 \mathrm{ml} / \mathrm{min}$ & $200 \mathrm{ml} / \mathrm{min}$ \\
\hline$<4$ & 42 & 63 & 84 \\
$4-5$ & 36 & 54 & 72 \\
$5-6$ & 30 & 45 & 60 \\
$6-7$ & 24 & 36 & 48 \\
$7-8$ & 18 & 27 & 36 \\
$>8$ & 12 & 18 & 24 \\
\hline
\end{tabular}

resting on the free wall of the right atrium, between the free edge and the atrioventricular junction.

After 5 minutes of antegrade reperfusion, retrograde infusion was begun with normothermic oxygenated blood mixed with a solution of potassium chloride $(0.5 \mathrm{mEq} / \mathrm{ml}$, $250 \mathrm{ml}$ ). The flow of retrograde normothermic oxygenated blood varied between 100 and $200 \mathrm{ml} / \mathrm{min}$, depending on the size and thickness of the ventricular wall and the pressure reached in the coronary sinus, which was continuously monitored and kept below $50 \mathrm{~mm} \mathrm{Hg}$.

The potassium chloride solution that was mixed with blood was infused continuously, with the dose based on the plasma level of potassium ion (which was determined every 15 to 20 minutes) and on the infusion rate reached in the retrograde perfusion, as specified in Table II, to maintain at all times a concentration of $20 \mathrm{mEq} / \mathrm{L}$ of potassium in the blood circulating through the coronary veins.

The routine of implantation was then begun, and an aspiration line was connected to the aortic root cannula to vent venous blood returning from the coronary ostia. Finally, the aortic anastomosis was performed, the potassium chloride infusion was discontinued, so that once the suture was completed air in the cavities was expelled by the spontaneous heart beat.

Parameters studied. The following data were collected during the preoperative period: age, sex, blood group, diagnosis, previous cardiac operations, status at the time of operation (at home, admitted to hospital, on ward or in the intensive care unit, and with or without circulatory assistance), urgent or elective operation, and hemodynamic data (mean aortic pressure, left ventricular diastolic pressure, pulmonary artery systolic pressure, transpulmonary gradient, pulmonary vascular resistance, cardiac output, and ejection fraction).

With respect to the donor, the following were studied: the distance from donor site (local, from the community, or long distance), age, sex, the number of days in the intensive care unit, and the need for and dose (up to or more than $10 \mathrm{mg} \cdot \mathrm{kg}^{-1} \cdot \mathrm{min}^{-1}$ ) of catecholamines. The donor was classified as suboptimum if any of the following criteria existed: age older than 45 years, previous cardiac arrest, catecholamine use greater than 10 $\mathrm{mg} \cdot \mathrm{kg}^{-1} \cdot \mathrm{min}^{-1}$ and weight below $80 \%$ of the recipient's weight.

The operative data collected were as follows: the ischemic time, the time of extracorporeal circulation, and the time to complete all sutures (graft implantation time). We also observed the time to resumption of a spontaneous 
Table III. Recipient preoperative data

\begin{tabular}{lccc}
\hline & Group $A$ & Group $B$ & $p$ \\
\hline No. of patients & 15 & 22 & \\
Age (yr) & $51.5 \pm 13.4$ & $51.4 \pm 14.7$ & NS \\
Sex $(n)$ & & & \\
$\quad$ Male & 12 & 20 & NS \\
$\quad$ Female & 3 & 2 & NS \\
Etiology $(n)$ & & & \\
$\quad$ Idiopathic & 8 & 11 & NS \\
Ischemic & 5 & 7 & NS \\
Others & 2 & 3 & NS \\
$\quad$ Reoperation & 2 & 4 & NS \\
Status (n) & & & \\
$\quad$ At home & 12 & 16 & NS \\
$\quad$ Urgent & 3 & 2 & NS \\
ICU & 1 & 3 & NS \\
Circulatory assistance & 1 & 1 & NS \\
\hline
\end{tabular}

$N S$, Not significant; $I C U$, intensive care unit.

beat after aortic declamping, problems in weaning from cardiopulmonary bypass ("normal," without inotropic drugs or with isuprel as used chronotrope, or "inotropic," with catecholamine support), and the presence or absence of spontaneous stable sinus rhythm at the end of the operation.

After the operation, the mean cardiac output was repeatedly determined during the first 12 hours. Hemodynamic stability was defined when patients did not need inotropic support. The number of days with catecholamine support was also recorded. The presence or absence of arrhythmias and their types (supraventricular or ventricular) and the need for temporary epicardial pacemaker were also observed. The peak creatine kinase level, total pericardial drainage, total number of transfused blood units, and reoperation for haemostasis or decompression were also noted. Finally, the total number of hours of endotracheal intubation and the intensive care unit and hospital stays were recorded.

The first endomyocardial biopsy specimen (obtained between the seventh and the tenth postoperative days) was reviewed to assess the presence or absence of myofibrillar necrosis without inflammatory infiltration, indicative of ischemic damage or secondary damage from catecholamines. Mortality rate within the first 30 days after operation was noted. Between the thirtieth and fortieth postoperative days, the systolic and diastolic pressures of the right ventricle, the ejection fraction, and the cardiac output were measured.

Statistical analysis. First, the homogeneity of the patients was determined. Once this homogeneity had been confirmed, studies were carried out on the relationships between perioperative variables, results of the first biopsy (seventh to tenth postoperative day), and results of the first hemodynamic study (thirtieth to fortieth postoperative day) in both groups. The quantitative variables were expressed as mean \pm standard deviation and were evaluated, after Snedecor's $F$ variance analysis was carried out, by comparison of the averages of the Student's $t$ test. The qualitative variables were evaluated by the $x^{2}$ test, with Yates' correction factor. Fisher's Exact Test was applied
Table IV. Donor characteristics

\begin{tabular}{lccc}
\hline & Group $A$ & Group $B$ & $p$ \\
\hline Local $(n)$ & 2 & 5 & NS \\
Community $(n)$ & 1 & 6 & NS \\
At distance $(n)$ & 12 & 11 & NS \\
Age (yr) & $25.4 \pm 10.4$ & $25.5 \pm 7.1$ & NS \\
Sex $(n)$ & & & \\
$\quad$ Male & 13 & 18 & NS \\
$\quad$ Female & 2 & 4 & NS \\
ICU stay (days) & $3.5 \pm 2.5$ & $2.3 \pm 2.6$ & NS \\
Inotropic support $(n)$ & & & \\
$\quad$ None & 4 & 11 & NS \\
$\quad 0-10 \mu \mathrm{g} \cdot \mathrm{kg}^{-1} \cdot \mathrm{min}^{-1}$ & 7 & 7 & NS \\
$\quad>10 \mu \mathrm{g} \cdot \mathrm{kg}^{-1} \cdot \mathrm{min}^{-1}$ & 1 & 2 & NS \\
Suboptimum $(n)$ & 6 & 8 & NS
\end{tabular}

Inotropic support refers to dopamine or dobutamine infusion. $N S$, Not significant; ICU, intensive care unit.

in those cases with an expected frequency below 5 . Probability values below 0.05 were taken as statistically significant.

\section{Results}

No significant differences were observed in the following data, which show the homogeneity for both groups with respect to the preoperative assessment of the recipient and characteristics of the donor (Tables III and IV).

Recipient preoperative data. Patients in both groups were similar with respect to age, sex, cardiac diagnosis, previous operations, and preoperative status. There were no significant differences in preoperative hemodynamic measurements between the hypothermic (group A) and the reperfusion group (group B). This was also true of the ejection fraction $(26 \% \pm 13.2 \%$ vs $23.4 \% \pm 10.9 \%)$, pulmonary vascular resistences $(3.2 \pm 1.5$ Wood units vs $2.4 \pm$ 1.3 Wood units), or transpulmonary gradient ( $7.5 \pm$ $4.9 \mathrm{~mm} \mathrm{Hg}$ vs $8 \pm 5.2 \mathrm{~mm} \mathrm{Hg}$ ).

Donor data. The most relevant donor data are summarized in Table IV. There were no significant differences between groups.

Intraoperative data. The ischemic time in group $B$ was 31 minutes less than that of group $A$, but the difference was not significant $(p=0.08$; Table V). Continuous reperfusion of the graft (group B) carried a certain degree of technical difficulty, which was reflected in the longer (by 12 minutes) time needed to complete the suture lines (67.3 minutes vs 55.3 minutes; $p=0.009$ ), but the time on extracorporeal circulation for both groups was the same (125 minutes), as was the overall time for implantation of the heart. 
In Fig. 1, the different surgical times (ischemia, suture, reperfusion, and extracorporeal circulation times) are represented. The time spent in the harvesting and transportation is the same in both groups, and the cardiopulmonary bypass time was also the same. Several differences were found. In group A, after a short period of trimming, we performed the implantation in 55.3 minutes. The heart was then reperfused, the total ischemic time was 178.8 minutes. In group B, trimming took longer because of the introduction of the canulas and the administration of the initial reperfusion. However the total ischemic time was 147.7 minutes, 31 minutes less than in group A. Implantation was performed in 67.3 minutes, while the heart was reperfused with controlled pressure and flow, in a systole at normothermia and with ventricles empty (Fig. 1). After release of the aortic crossclamp, the heart resumed a spontaneous rhythm in only two cases in group A. In contrast, in Group B spontaneous resumption ocurred in practically all cases $(20 / 22 ; p<$ $0.001)$. With respect to weaning from extracorporeal circulation, there were no differences in the need for inotropic support (four cases in group A and six in group B), although there was a tendency toward greater stability of sinus rhythm in the reperfusion group ( $p=0.08$; Table V).

Postoperative data. Cardiac output and hemodynamic stability in the first $\mathbf{1 2}$ hours after operation were similar in the two groups (Table VI). On the other hand, the number of days that inotropic support for cardiac function or rate was necessary was significantly lower in group B (3.1 days) than in group A (6 days; $p=0.02$ ). The incidence of arrhythmia was also significantly lower in group B $(8 / 22)$ versus group A $(11 / 15 ; p=0.04)$.

Differences were not found in maximum creatine kinase levels, pericardial drainage, or transfused units of blood. There were no differences in the number of hours of endotracheal intubation or in in-hospital mortality rate. The causes of death were early graft failure for one patient in group A and one patient in group $B$ and multiorgan failure in the other two patients in group B who died (Table VI). None of the patients in group B had more clinical or hemodynamic evidence of right ventricular dysfunction than seen in group A patients.

On the other hand, there was a significant difference in length of intensive care unit and hospital stays, which were significantly less for group B than for group A ( $p<0.0001$ and $p<0.01$, respectively). There was no change in medical management of patients during this time period.
Table V. Intraoperative data

\begin{tabular}{lccc}
\hline & Group $A$ & Group $B$ & $p$ \\
\hline Ischemic time (min) & $178.8 \pm 55.1$ & $147.7 \pm 61.2$ & 0.08 \\
CPB time (min) & $125 \pm 72.3$ & $124.2 \pm 40$ & NS \\
Suture time (min) & $53.3 \pm 18.7$ & $67.3 \pm 15.9$ & 0.009 \\
Spontaneous beating $(n)$ & 2 & 20 & $<0.001$ \\
Weaning from CPB $(n)$ & & & \\
$\quad$ Normal & 11 & 16 & NS \\
$\quad$ Inotropic support & 4 & 6 & NS \\
Stable SR & 8 & 18 & 0.08 \\
\hline
\end{tabular}

$C P B$, Cardiopulmonary bypass; $N S$, not significant; $S R$, sinus rhythm.

In all endomyocardial biopsy samples obtained between the seventh and tenth postoperative days in group A, isolated foci of myofibrilar necrosis of ischemic origin were found. No evidence of ischemia was noted in nine $(45 \%)$ of the 20 biopsy samples obtained in group B $(p<0.01)$.

Hemodynamic studies done on the thirtieth and fortieth postoperative days showed significantly lower right ventricular pressures, both systolic and diastolic, in group $\mathrm{B}(p=0.03$ and $p=0.04$, respectively) compared with group $\mathrm{A}$. There were no differences in ejection fraction and cardiac output, which were normal in both groups (Table VII).

\section{Discussion}

This continuous warm reperfusion technique is an attempt at reducing as much as possible ischemic time and reperfusion damage in an effort to "rescue" areas of the myocardium that were not irreversibly damaged by storage of the donor heart. It is known that the conditions under which reperfusion is carried out are of great importance. Allen, Okamoto, and Buckberg ${ }^{19}$ and Okamato and colleagues ${ }^{20}$ showed that in coronary artery operations, myocardial contractility is preserved after prolonged ischemic periods, if reperfusion is performed with low pressure and flow, even more so if reperfusion is carried out for 10 minutes. Chambers, Takahashi, and Hearse ${ }^{23}$ came to the same conclusions regarding experimental heart transplants perfused under hypothermia. Kirklin and associates ${ }^{11}$ have recommended that the pressure in the aortic root should not exceed $60 \mathrm{~mm} \mathrm{Hg}$ when reperfusion in human heart transplantation is carried out under normothermia with blood cardioplegia.

We tried to reduce the temperature gradient between the reperfused blood and the myocardium. This allowed a progressive rewarming of the graft after its removal from the refrigerator, maintenance at room temperature during trimming, and mainte- 

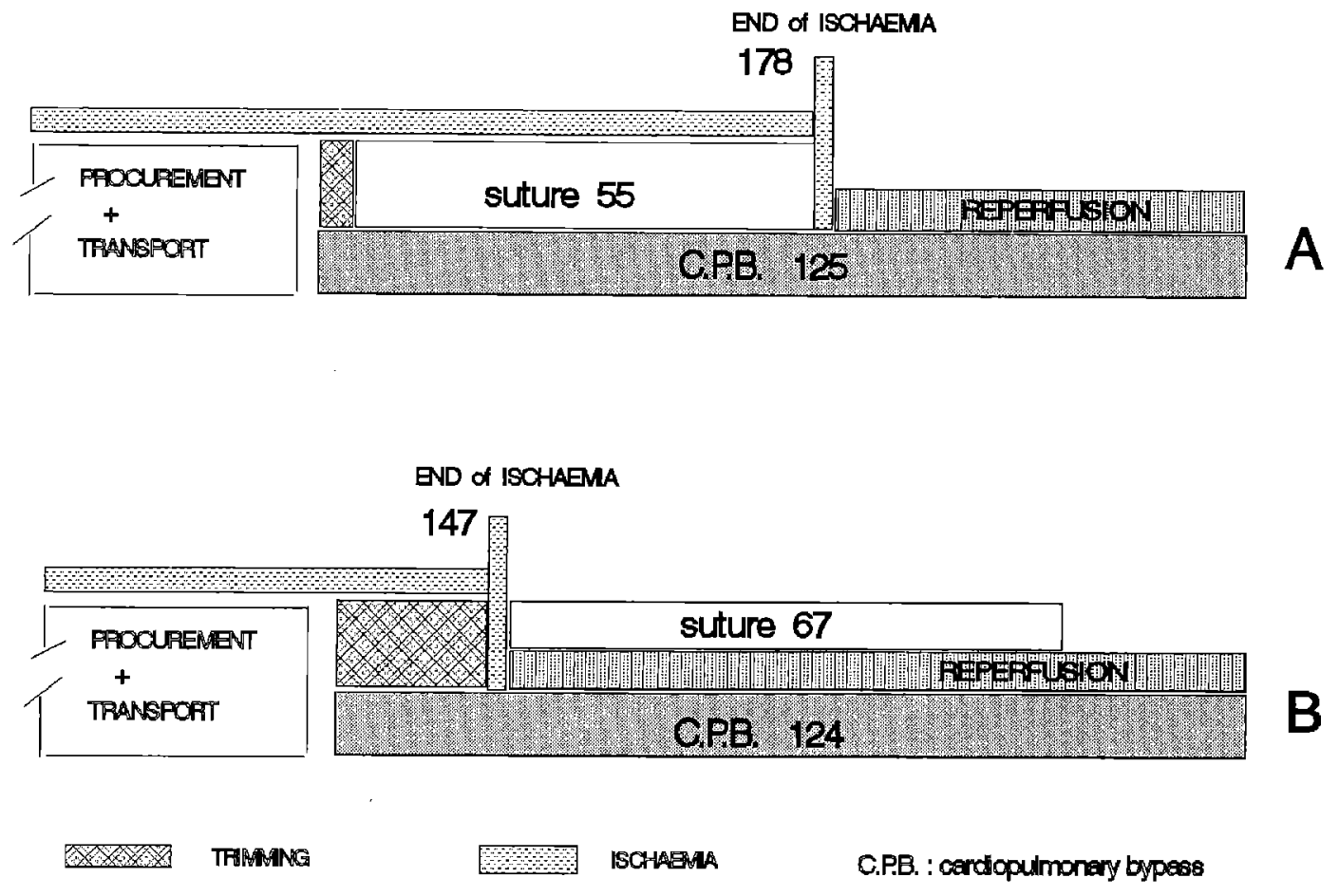

Fig. 1. Schematic representation of the different surgical times (minutes) in groups A (A) and B (B).

Table VI. Postoperative data

\begin{tabular}{|c|c|c|c|}
\hline & Group $A$ & Group $B$ & $p$ \\
\hline Cardiac output (L/min) & $6.4 \pm 1.2$ & $7.3 \pm 1.9$ & NS \\
\hline Hemodynamic stability $(n)$ & 11 & 10 & NS \\
\hline Inotropic support (days) & $6 \pm 2.3$ & $3.1 \pm 1.1$ & $<0.02$ \\
\hline \multicolumn{4}{|l|}{ Arrhythmias $(n)$} \\
\hline None & 4 & 14 & $<0.04$ \\
\hline Supraventricular & 4 & 2 & NS \\
\hline Ventricular & 3 & 1 & NS \\
\hline Pacemaker required & 4 & 5 & NS \\
\hline Creatine kinase (units) & $1188 \pm 639$ & $1006 \pm 523$ & NS \\
\hline Total drainage (ml) & $1450 \pm 1291$ & $1367 \pm 1106$ & NS \\
\hline Blood transfused (units) & $4.8 \pm 5.5$ & $2.7 \pm 2.4$ & NS \\
\hline Reoperation (n) & 3 & 3 & NS \\
\hline $\begin{array}{l}\text { Mechanical ventilation } \\
\text { (hr) }\end{array}$ & $24.7 \pm 23.1$ & $23.6 \pm 27.2$ & NS \\
\hline ICU stay (days) & $7.4 \pm 2.1$ & $4.7 \pm 1.4$ & $<0.0001$ \\
\hline Hospital stay (days) & $15.6 \pm 5$ & $10.7 \pm 3.6$ & $<0.01$ \\
\hline $\begin{array}{l}\text { No ischemia at first endo- } \\
\text { myocardial biopsy }(n)\end{array}$ & 0 & $9(45 \%)$ & $<0.01$ \\
\hline Hospital mortality $(n)$ & 1 & 3 & NS \\
\hline
\end{tabular}

$N S$, Not significant; ICU, intensive care unit.

nance at room temperature thereafter by infusion of the initial dose of perfusate at $30^{\circ}$ to $32^{\circ} \mathrm{C}$.

With respect to the composition of the reperfusion solution, in the initial dose we use the same solution as that of Buckberg, ${ }^{10}$ but with a high concentration of potassium ${ }^{11,24}$ to maintain asystole
Table VI. Cardiac catheterization, first postoperative month

\begin{tabular}{lccc}
\hline & Group A & Group B & $p$ \\
\hline $\begin{array}{l}\text { Right ventricular systolic } \\
\text { pressure (mmHg) }\end{array}$ & $36.7 \pm 11.9$ & $26.6 \pm 6.4$ & $<0.003$ \\
$\begin{array}{l}\text { Right ventricular diastolic } \\
\text { pressure (mmHg) }\end{array}$ & $5.5 \pm 12.5$ & $3.5 \pm 2.6$ & $<0.04$ \\
Ejection fraction (\%) & $64.7 \pm 6.1$ & $64.6 \pm 11.2$ & $\mathrm{NS}$ \\
Cardiac output (L/min) & $6.9 \pm 2.2$ & $6 \pm 1.2$ & $\mathrm{NS}$ \\
\hline
\end{tabular}

during the initial phase of implantation. The addition of substrates such as glutamate seems to improve recovery of ventricular function after prolonged ischemia in conventional operations ${ }^{7,9}$ as well as in heart transplantation after cold storage. ${ }^{8}$

We chose the retrograde route for cardioplegia administration because it does not interfere with the construction of the anastomoses. There is thus assurance of continuous perfusion throughout the procedure. If antegrade cardioplegia is used, it is necessary to maintain aortic valve competence. Perfusion has to be discontinued during the aortic anastomosis, which leads to a period of normothermic ischemia and possible reperfusion damage. The hemodynamic performance of the right ventricle 1 month after operation appeared better than that 
observed with the conventional technique, suggesting adequate distribution of flow with retrograde cardioplegia.

With continuous reperfusion of the graft with oxygenated blood under normothermia during cardiac implantation, reduction of ischemic time was achieved, as shown by Menasché, ${ }^{14}$ who begins reperfusion after suture of the left atrium. With our technique, ischemia is further reduced (up to 30 minutes in total) if reperfusion is begun at the moment of the graft's removal from the refrigerator. This makes it possible to increase the safe time span for procurement and enlarges the pool of possible donors.

The greater complexity of the technique implies lengthening the suture time for the graft by 12 minutes. There is no increase in the cardiopulmonary bypass time, however, and the hemostatic quality of the sutures appears not to be jeopardized, because the total volume of bleeding and the frequency of reoperation remain the same.

Surgeons who use intermittent doses of cold blood cardioplegia during implantation and subsequent reperfusion with warm blood cardioplegia have found this method superior to the conventional technique with respect to the incidence of spontaneous defibrillation, return to sinus rhythm, time of mechanical ventilation, and the need for, dosage of, and duration of dopamine administration. ${ }^{12,13} \mathrm{We}$ observed spontaneous return of cardiac function in $90.9 \%$ of cases. The hemodynamic status at time of weaning from bypass was similar to that noted with the conventional technique. On the other hand, stable sinus rhythm resumed at the end of the operation when reperfusion was used, associated with a lower incidence of arrhythmias after operation. $^{12,13}$ The duration of catecholamine administration was reduced with continuous reperfusion. There was no change, however, in the number of hours of mechanical ventilation, as observed by others. ${ }^{12,13}$ Intensive care unit and hospital stays are reduced when continuous normothermic reperfusion is used. There was no difference in mortality rate in the first 30 days between hypothermic and normothermic groups.

Although operative mortality rate, transmural infarction, need for defibrillation, and need for inotropic support or counterpulsation are nonspecific and insensitive indicators of myocardial damage, ${ }^{25}$ these parameters are cited in the various studies in the literature. To improve the reliability of these studies, it would be necessary to carry out serial enzymatic determinations, radioisotope ventricular function studies, and regional ventricular wall motion studies with transesophageal echocardiography. These studies are difficult to perform because of the logistic complexity, involving the donor hospital and later follow-up at another institution where the heart is implanted.

\section{Conclusions}

It is technically feasible to perform cardiac transplantation with continuous coronary perfusion during implantation of the heart. The ischemic time is reduced, with consequent increase in the donor pool availability. Defibrillation and return to spontaneous sinus rhythm ocurred in most of the cases. There was a lower incidence of arrhythmias in the normothermic group during the immediate postoperative period. There was evidence of less ischemia in the first endomyocardial biopsy specimen. One month after operation, the right ventricular pressures were lower. Echocardiographic studies before and after harvesting could confirm the superiority of continuous coronary perfusion during implantation, allowing the surgeon to "rescue" donor hearts usually rejected for use in cardiac transplantation.

\section{REFERENCES}

1. Kriett JM, Kaye MP. The registry of the International Society for Heart and Lung Transplantation: eighth official report1991. J Heart Lung Transplant 1991;10:491-8.

2. Wahlers T, Cremer J, Fieguth G, et al. Donor heart-related variables and early mortality after heart transplantation. $\mathbf{J}$ Heart Lung Transplant 1991;10:22-7.

3. Wheeldon D, Sharples L, Wallwork J, English T. Donor heart preservation survey. J Heart Lung Transplant 1992;11: 986-93.

4. Cabrol C, Gandjbakhch I, Pavie A, et al. Current problems in cardiac transplantation. Biomed Pharmacother 1989;43:8792.

5. Uretsky BK. Physiology of the transplanted heart. In: Brest AN, ed. Cardiovascular clinics. Philadelphia: FA Davis, 1990:23-56.

6. Bolli R. Myocardial "stunning" in man. Circulation 1992;86: 1671-91.

7. Buckberg GD. Studies of controlled reperfusion after ischemia: I. When is cardiac muscle damaged irreversibly? J Thorac Cardiovasc Surg 1986;92:483-7.

8. Fleckenstein A, Frey M, Fleckstein-Grün G. Consequences of uncontrolled calcium entry and its prevention with calcium antagonists. Eur Heart J 1983;4(Suppl 2):43-50.

9. Wiese S, Askanazi J. Glucose/insulin/potassium therapy: a reevaluation of myocardial benefits during cardiopulmonary bypass. J Cardiothorac Vasc Anesth 1992;6:517-20.

10. Buckberg GD. Antegrade/retrograde blood cardioplegia to ensure cardioplegic distribution: operative techniques and objectives. J Card Surg 1989;4:216-38.

11. Kirklin JK, Neves J, Naftel DC, Digerness SB, Kirklin JW, Blackstone EH. Controlled initial hyperkalemic reperfusion 
after cardiac transplantation: coronary vascular resistance and blood flow. Ann Thorac Surg 1990;49:625-31.

12. Nataf P, Pavie A, Bracamontes L, Bors V, Cabrol C, Gandjbakhch I. Myocardial protection by blood cardioplegia and warm reperfusion in heart transplantation. Ann Thorac Surg 1992;53:525-6.

13. Soots G, Crepin F, Prat A, et al. Cold blood cardioplegia and warm cardioplegic reperfusion in heart transplantation. Eur $\mathbf{J}$ Cardiothorac Surg 1991;5:400-5.

14. Menasché P. Myocardial preservation: technology and future trends. Role of normothermic blood cardioplegia in cardiac transplantation. Atlanta: October 16-17, 1992.

15. Salerno TA, Houck J, Barrozo CA. Retrograde continuous warm blood cardioplegia: a new concept in myocardial protection. Ann Thorac Surg 1991;54:245-7.

16. Pradas G, Juffé A, Castillo-Olivares JL, Olivier C, Burgos R, Figuera D. Extracción y conservación del corazón donante. Clin Cardiovasc 1985;3(1):10-2.

17. Pradas G, Juffé A. Técnica de extracción y conservación del corazón donante: programa de trasplante cardíaco. Hospital Juan Canalejo. Galicia Clin 1992;64:47-9.

18. Allen BS, Okamoto F, Buckberg GD. Studies of controlled reperfusion after ischemia: IX. Reperfusate composition: benefits of marked hypocalcemia and diltiazem on regional recovery. J ThORAC CARDIOvaSC SuRg 1986;92:564-72.

19. Allen BS, Okamoto F, Buckberg GD. Studies of controlled reperfusion after ischemia: XII. Effects of "duration" of reperfusate administration versus reperfusate "dose" on regional function, biochemical, and histological recovery. J Thorac Cardiovasc Surg 1986;92:594-604.

20. Okamoto F, Allen BS, Buckberg GD, Bugyi H, Leaf J. Studies of controlled reperfusion after ischemia: XIV. Reperfusion conditions: importance of ensuring gentle versus sudden reperfusion during relief of coronary occlusions. J Thorac Cardiovasc Surg 1986;92:613-20.

21. Lichtenstein SV, Ashe KA, El-Dalati H, Cusimano RJ, Panos A, Slutsky AS. Warm heart surgery. J THORAC CARDIOvaSC SURG 1991;101:269-74.

22. Salerno TA. Invited letter concerning: myocardial temperature management during aortic clamping for cardiac surgery-protection, preoccupation, and perspective. J THORAC CARDIOVASC SuRg 1992;103:1019-20.

23. Chambers DJ, Takahashi A, Hearse DJ. Long-term preservation of the heart: the effect of infusion pressure during continuous hypothermic cardioplegia. J Heart Lung Transplant 1992;11:665-75.

24. Follette DM, Fey KH, Steel DL. Reducing reperfusion injury with hypocalcemic, hyperkalemic, alkalotic blood during reoxygenation. Surg Forum 1978;29:284-6.

25. Lell WA. Hot or cold, continuous or intermittent? What goes around comes around. J Cardiothorac Vasc Anesth 1992;6: 125-6.

\section{Availability of JouRnAL back issues}

As a service to our subscribers, copies of back issues of THE Journal of Thoracic and Cardiovascular Surgery for the preceding 5 years are maintained and are available for purchase from the publisher, Mosby-Year Book, Inc., at a cost of $\$ 13.50$ per issue. The following quantity discounts are available: $25 \%$ off on quantities of 12 to 23 , and one third off on quantities of 24 or more. Please write to Mosby-Year Book, Inc., Subscription Services, 11830 Westline Industrial Drive, St. Louis MO 63146-3318, or call 800-453-4351 or 314-453-4351 for information on availability of particular issues. If unavailable from the publisher, photocopies of complete issues are available from University Microfilms International, 300 N. Zeeb Rd., Ann Arbor, MI 48106, 313-761-4700. 